\title{
Absence of a specific effect of free radicals on HLA-B27
}

\author{
I L MacLean, M W Lowdell, D R Blake, J Lunec, J R Archer
}

\begin{abstract}
The spondylitis associated HLA-B27 epitope includes a characteristic unpaired cysteine at amino acid position 67 . On some B27 molecules the thiol (-SH) side chain of this residue seems to be available for chemical interactions. The possibility that free radicals produced during inflammation might specifically affect this group was investigated in this work. Cells bearing HLA-B27 were exposed to free radicals generated by ultraviolet irradiation or hydrogen peroxide, and HLA antigens were then measured by flow cytometry. Binding of monoclonal antibodies to B27 was not affected. These results do not support a specific susceptibilty of HLA-B27 to damage by free radicals, despite its apparently vulnerable structure.
\end{abstract}

(Ann Rheum Dis 1992; 51: 963-964)

HLA-B27 is associated with a number of inflammatory diseases, including the seronegative spondarthropathies. ${ }^{1}$ Sequence studies indicate an epitope with an unpaired cysteine at amino acid position 67. Substitution of this position by large amino acids causes the loss of B27 specificity, ${ }^{2}$ and treatment of B27 positive cells with $p$-chloromercuriphenylsulphonic acid, which reacts with free thiols, causes specific partial blocking of the antigenic activity of a proportion of B27 molecules. ${ }^{3}$

Thiol groups are particularly prone to damage by free radicals. ${ }^{4}$ Small alterations to histocompatibility antigens result in vigorous immunological rejection reactions, and damage by free radicals to the epitope of B27 could mimic such changes. We thought that the association of B27 with disease might involve damage by free radicals produced during inflammation. We therefore investigated whether treatment with systems generating free radicals caused specific damage to the B27 antigen.

\section{Materials and methods}

Hom-2, a well characterised B lymphoblastoid cell line homozygous for HLA-A3 and B27, was maintained in RPMI 1640 medium (GIBCO, Paisley, UK) containing $10 \%$ fetal calf serum, benzylpenicillin $(100 \mathrm{IU} / \mathrm{ml})$, and streptomycin $(100 \mu \mathrm{g} / \mathrm{ml}$ ) (tissue culture medium). Monoclonal antibodies to HLA-A3 and -B27 were used as ascitic fluids derived from the GAP-A3 and B27.M1 hybridomas respectively. ${ }^{3}$

The generation of free radicals by ultraviolet irradiation and determination of the free radicals produced by phenol red oxidation enzyme linked immunosorbent assay (ELISA) were as described previously. ${ }^{6}$

Cells were washed three times in ice cold phosphate buffered saline (PBS) then resuspended at a concentration of $1.5 \times 10^{6} \mathrm{cells} / \mathrm{ml}$ in ice cold freshly prepared solutions of: $(a) 0-1$ mM p-chloromercuriphenylsulphonic acid (Aldrich, Poole, UK) in PBS for 30 minutes; (b) 0-100 mM hydrogen peroxide in PBS, with or without $10 \mu \mathrm{M}$ copper(II) sulphate for 30 minutes; or $(c)$ ultraviolet irradiated tissue culture medium, for three hours. Cells treated with free radicals and control cells were washed then incubated for 30 minutes on ice with monoclonal antibodies to HLA in PBS with 1\% bovine serum albumin and $0.02 \%$ sodium azide, washed, then incubated for a further 30 minutes in fluorescein conjugated $F\left(a b^{\prime}\right)_{2}$ fragments of
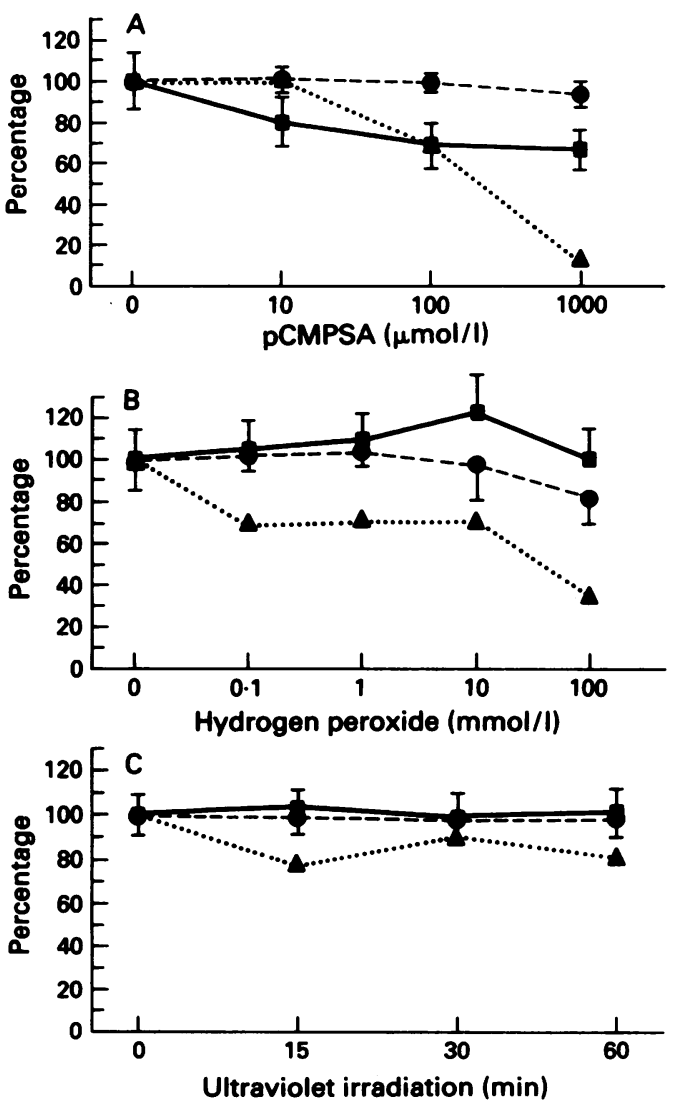

Effect of $(A)$ p-chloromercuriphenylsulphonic acid ( $D C M P S A),(B)$ hydrogen peroxide, and $(C)$ ultraviolet irradiation on recognisable cell surface $H L A-B 27$ (binding of $B 27 . M 1$ monoclonal antibody; - ) and $H L A-A 3$ (GAP-A 3 monoclonal antibody; ---0$)$, and on cell viability (propidium iodide exclusion; $\mathbf{\Delta} \cdot \cdots$ ). Markers on antibody curves correspond to the mean fluorescence channel, and error bars represent the coefficient of variability. Results are expressed as a percentage, relative to the corresponding values for untreated controls. 
rabbit antimouse immunoglobulin (Dako F313). Labelled lymphoblastoid cell lines were analysed on a Becton Dickinson FacScan and the mean fluorescence intensity for binding of each monoclonal antibody to treated cells was compared with that of controls. The viability of the cells after treatment was assessed by $0.005 \%$ propidium iodide dye exclusion; cytometer gating for fluorescence analysis was set to include live and dead cells, but to exclude subcellular debris.

\section{Results}

The species of free radicals generated by 60 minutes of ultraviolet irradiation included the equivalent of $160 \mu \mathrm{M}$ hydrogen peroxide, as estimated by phenol red oxidation. The effects on recognisable cell surface HLA-B27 and -A3, and on the viability of Hom- 2 cells exposed to $p$ chloromercuriphenylsulphonic acid, hydrogen peroxide, and ultraviolet irradiation tissue culture medium are shown in the figure. $p$ Chloromercuriphenylsulphonic acid (positive control) produced an approximately 30\% decrease in recognisable cell surface HLA-B27, but did not affect the control antigen A3. The direct action of hydrogen peroxide alone did not alter B27, and the addition of copper(II) ions, intended to promote the generation of hydroxyl $\left(\bullet^{\bullet} \mathrm{OH}\right)$ radicals from hydrogen peroxide, had no additive effect with hydrogen peroxide. Free radicals generated by ultraviolet irradiation had no effect on the antigenic activity of either B27 or A3 (figure).

\section{Discussion}

Treatment of hydrogen peroxide with copper ions causes the production of hydroxyl radicals, whereas ultraviolet irradiation of aqueous media induces the production of a variety of reactive oxygen derived free radicals, including superoxide ions. Our experiments suggest that none of these affects the HLA-B27 epitope, despite its unpaired, potentially reactive cysteine molecule. We have previously shown that ultraviolet irradiation and hydrogen peroxide used in similar protocols can react with cysteine residues on immunoglobulin molecules. ${ }^{4}$

Our conclusion depends on the assumption that a change caused by free radicals would be measurable as a change in the antigen recognised by monoclonal antibody. The sensitivity of this technique for detecting small changes in HLAB27 is limited. The B27.M1 monoclonal antibody, as with most monoclonal antibodies to HLA-B27, does not discriminate between six naturally occurring HLA-B27 subtypes; moreover, only some of the in vitro B27 variants ${ }^{2}$ are discriminated by differences in the binding of monoclonal antibody. Although our previous results show that the antibody B27.M1 detects the addition of large negatively charged, aromatic substituents to B27, they can also be interpreted as showing that small oxidative changes are not detectable by this technique. ${ }^{3}$ Thus the demonstration of putative damage by free radicals to HLA-B27 may await the development of a more sensitive assay for altered B27.

It seems likely that damage by free radicals to whole cells is relatively non-specific. The reaction temperature and the duration of cell exposure to free radicals were reduced in this study to minimise damage dependent on cellular metabolism rather than on the immediate chemical effects of free radicals. As intact cells were used, the free radicals generated are likely to have had a predominant effect on membrane lipids, which are in vast excess over proteins at the cell surface.

We thank Mr I V J Archer for his conscientious technical assistance. This work was supported by a grant from the Arthritis and Rheumatism Council. ILM was recipient of a Commonwealth Medical Research Scholarship.

1 Moll J M H, Haslock I, Wright V. Seronegative arthritides. In: Scott J T, ed. Copeman's textbook of the rheumatic diseases. 6th ed. Edinburgh: Churchill Livingstone, 1986: $723-44$.

2 El-Zaatari F A K Sams K C Taurog J D In vitro mutagenesis of HLA-B27. Amino acid substitutions at position 67 disrupt anti-B27 monoclonal antibody binding in direct relation to the size of the substituted side chain. $\mathcal{F}$ Immunol 1990; 144: 1512-7.

3 MacLean L, Macey M, Lowdell M, et al. Sulphydryl reactivity of the HLA-B27 epitope: accessibility of the free cysteine studied by flow cytometry. Ann Rheum Dis 1992; 51: $456-60$.

4 Lunec J, Blake D R, McCleary S J, Brailsford S, Bacon P A. Self-perpetuating mechanisms of immunoglobulin $\mathbf{G}$ aggregation in rheumatoid inflammation. $\mathcal{F}$ Clin Invest 1985; 76: 2084-90.

5 Yang S Y, Milford E, Hammerling U, Dupont B. Description of the reference panel of B-lymphoblastoid cell lines for factors of the HLA system: the B-cell line panel designed for the tenth international histocompatibility workshop. In: Dupont B, ed. Immunobiology of $H L A$. Vol 1. New York: Springer-Verlag, 1989: 11-9.

6 Allan I M, Lunec J, Salmon M, Bacon P A. Reactive oxygen species selectively deplete normal $T$ lymphocytes via a hydroxyl radical dependent mechanism. Scand $f$ Immunol 1987; 26: 47-53. 